\title{
Metaphors to work by: the meaning of personal assistance in England
}

\section{Keywords}

disability, metaphor, independent living, cash for care.

\section{Introduction}

The UK and other high income countries have seen a growth in 'personalisation', where social services are provided on an individual basis, with more choice and control, rather than on a collective basis (Glendenning et al 2000). This governmental impetus has matched the demands of the disabled people's movement for control and independent living (Shakespeare 2014). Direct payments to individuals, for example, have enabled them to choose their own forms of support and assistance. The introduction of direct payments has created new roles and relationships, described as 'hybrid' forms of care (Ungerson, 1999). 'Personal assistant' is one such innovative role which has evolved out of the Independent Living Movement and is now commonplace in UK, Nordic countries and North America (Guldvik et al, 2014). Personal assistance is defined, in part, as a cash-for-care arrangement (Ungerson and Yeandle, 2005), although the meaning of the relationship itself remains contested.

In the classic Independent Living model, personal assistance was initially thought of as separating emotions from tasks. Direct remuneration ensured that the relationship was one of balanced exchange: one party provided support, the other provided money (Morris, 1997). For the first time, support was provided which bypassed negative imagery or feelings of dependency on family members (or other carers), or the necessity of expressing gratitude (Wood, 1991; Shakespeare, 2014). And for the first time too, the unequal power relationship between disabled people and the people who support them was transformed: disabled people were able to live in the community, they were in control (Morris, 1997) and a new 'profession allied to the community' was created (Finkelstein, 1999). 
Personal assistance has given disabled people more freedom and has enabled their social participation. When, and if, the right funding is in place, people no longer have to live in institutions, or to be dependent on family members or volunteers. Disabled people can choose who they want to support them, how they want to be supported, and to have greater control over their own lives (Morris, 1997). Personal assistance offers flexibility, empowerment and control (Glendinning et al, 2000), but it also requires people to become employers, to manage budgets, to process recruitment and to manage wages and taxes. With freedom comes hard work and responsibility. Freedom also means vulnerability, and our study found examples of abuse of disabled people by their workers.

For personal assistants, one positive aspect of personal assistance is that it provides flexible working conditions, which may be especially attractive to people seeking part-time or informal work. The negative side, however, is that personal assistance can also represent insecure, privatised and largely unregulated work (Glendenning et al, 2000; ILO, 2011; Ahlström and Wadensten, 2012). It entails long periods of solitary working, there is often little or no support or training available, and very few personal assistants are unionised (Pillinger, 2011; ILO, 2011). In the UK, there is no inspection of personal assistance by the (official) Care Quality Commission, unlike support provided in care homes, hospitals or other congregate settings, where inspections / regulation are mandatory.

Notwithstanding the Independent Living principles, personal assistance entails relationships and emotional connections. It is work that requires intimacy and trust and which occurs over a prolonged period of time. As such, it is likely to break down personal, social and professional barriers (Wadensten and Ahlström, 2009). Personal assistance work involves physical touch, shared activities and prolonged periods spent with another person; further, the workplace of one party is the home space of the other (Ungerson, 1999; Glendenning et al, 2000). 
For Woodin (2006), personal assistance work - involving physical proximity, intimate assistance, and tasks requiring trust - often results in relationships that resemble friendships. Yet while personal assistance relationships involve characteristic features of friendship (such as emotional attachment and shared interests), they also retain fundamental qualities of the employer-employee relationship. Accordingly, Woodin (2006) terms the personal assistance relationship 'paid friendship'. In a hybrid, 'paid friendship', relationship, it can be difficult to know how to feel or act towards the other person.

Every participant in Ungerson's (1999) study of personal assistance described the relationship as that of employer-employee, although other relational constructs (such as friendship) were also important. This picture is complicated further where disabled employers hire existing friends or neighbours; a situation which may result in rewarding relationships, but which can equally be emotionally fraught and painful. Personal assistants often lack clear job descriptions, specified working hours or clearly defined entitlements. Indeed, personal assistants often do not recognise their duties as 'work', per se, because of the close connection they feel towards their employer, and because many of their tasks are social in nature. Glendenning et al (2000) report that personal assistants often face confusion over both their duties and their feelings towards their employers.

In this paper, we use the idea of metaphors as a prism to understand these new relationships. 'Metaphor' can be defined as talking about one thing in terms of another, different, thing. Lakoff and Johnson (1980) have described the ways in which metaphors shape our everyday lives and functioning, down to the most mundane of details: 'Our ordinary conceptual system, in terms of which we both think and act, is fundamentally metaphorical in nature' (Lakoff and Johnson, 1980:3).

While metaphors promote communication and understanding by allowing us to draw on conventional or consensual ways of thinking, people are not even always aware that they are using them. Ever since Lakoff and Johnson (1980) published their analysis, research on metaphors, as a cognitive function that establishes our reality, has proliferated in the social 
sciences (Martin, 1991; Moore, 2004; Maasen, 2000) and (especially) in the so-called 'hard' sciences. Metaphors allow scientists to describe their research in an 'as-if' way, to render their knowledge shareable with others both within and outside their scientific community (Maasen et al 1995).

The concepts by which we think also shape the ways we perceive the world and how we relate to others. Metaphors both highlight and hide aspects of our experience. Metaphor frames topics, highlighting some aspects and backgrounding others (Lakoff and Johnson, 1980). Metaphors have evaluative functions (Deignan, 2010); this happens, for example, when literal meanings have connotations, or entailments, or align the speaker with a group, or trigger scenarios. When we describe our reality in a particular way, then the words and phrases we use come with a cultural 'baggage'.

Metaphor research is found, for example, in social studies of cancer, ever since Susan Sontag talked about 'illness as metaphor' (1978). More recently, Semino et al (2017) have explored the use of violence and journey metaphors by patients with cancer, and by health professionals. These metaphors can be empowering and disempowering, depending on context. They offer a way of talking about abstract and complex experiences in concrete and simple terms. They also frame the issue of cancer, perhaps as a fight or as a journey. Semino et al (2017) found that metaphors were more frequently used by patients than by professionals.

Because we create metaphors from thinking patterns that are already familiar to us, they allow us to deal with situations that are new to us, and to communicate situations that are new to others. We use the 'as if' character of metaphors to integrate new experiences within our existing cognitive system of how we structure the world around us. This makes the concept of metaphor very apposite in the context of personal assistance, which is an innovative form of care and a new and almost unprecedented type of social relationship. Personal assistance has no fixed and settled meaning, and offers no agreed model to follow. 


\section{Methodology}

The data presented in this paper are taken from a study entitled 'Personal Assistance and Disabled People: Emotions, Ethics and Power', funded by the UK Economic and Social Research Council [ES/L007894/1]. The aims of the study were to gain a better understanding of the relationships that occur when disabled people directly employ personal assistants, and to explore how both parties experience and manage challenges within these relationships.

\section{Sampling and recruitment}

Disabled informants were sampled using purposive sampling. Disabled informants were identified and recruited through a network of disabled people's organisations. A sampling frame was developed and implemented to guard against parochialism and to ensure that we captured a variety of experiences. The sampling frame included disabled people's organisations in both rural and urban areas, and we purposively sampled both non-white-British informants and a range of impairments, including congenital impairments and those acquired in later life. Exclusion criteria included being under the age of 18 years and lacking mental capacity to provide informed consent.

Personal assistant informants were sampled initially using purposive sampling and later through snowball sampling, and recruited through informal contacts within the same network of disabled people's organisations, through blogs, and by advertising the study on a national internet-based personal assistant forum; the informants garnered through these efforts provided further contacts (snowball sampling).

\section{Data collection}

Data collection took place between 2015 and 2017. Disabled informants were offered three modes of interview: face to face, telephone or email. Email correspondence was offered as an alternative to verbal interviews for informants with impaired speech. The majority of disabled informants took part in a face to face interview, and all but one of these interviews took place in the informant's own home (the other was conducted in a public space). Personal assistant 
informants were offered two modes of interview: face to face or telephone. Most chose a telephone interview; these informants were geographically more dispersed than the disabled informants recruited for the study.

Interviews followed a topic guide informed by extant literature and refined iteratively throughout data collection. Where interviews were conducted using email, informants were sent a document containing a topic guide, which they annotated and returned to the research team. The majority of the interviews were conducted by TP, but TS and AS each conducted four interviews. All interviews were transcribed verbatim, with QSR Nvivo 11 used for data storage, administration and analysis.

The sample

Our 30 disabled interviewees comprised people with a broad range of impairments. They included, for example, six people with MS; four people with a neuromuscular impairment; three people with cerebral palsy; and two people with spinal cord injury. We interviewed three mothers who held personal assistance contracts on behalf of a son or daughter with learning disabilities (but did not interview any people with learning disabilities themselves). All interviewees were of white British origin apart from two British Asian and one Black British interviewee. The 28 personal assistants interviewed comprised six men and 22 women; 24 were of British origin, and four of other European origin. (Participant details are presented in Tables 1 and 2.)

\section{Data analysis}

Constructivist Grounded Theory (Charmaz, 2006) provided the framework for analysis. The first stage of coding was 'initial coding', that is, coding marked by close attention, and sometimes line-by-line coding, which promotes attentiveness to detail and helps prevent larger excerpts of text being inaccurately coded through tacit assumptions. Following initial coding, increasingly directed and conceptually driven 'focused coding' was undertaken. Following Charmaz (2006), focused coding involved identifying and expanding the most theoretically significant and frequently occurring codes arrived at through initial coding. A final stage of 'theoretical coding' 
analysed categories of codes generated through focused coding. In practice, as recognised by Charmaz (2006), the distinction between each coding stage was flexible, with coding an emergent process: as concepts emerged, initial coding was revisited and re-coded in light of subsequent theoretical coding. The stages of focused and theoretical coding were subjected to peer review by all members of the research team, with the aim of cross validating data interpretation.

\section{Findings}

Data confirms that there is no single kind of personal assistance relationship. Just as disability itself is very diverse, so we found that different disabled people had different ways of approaching the employment and management of their workers. This reflects personality characteristics, and the life goals that the disabled individual was employing a personal assistant to enable them to achieve. There was a particular difference between those people who had been active in the disability rights community, and those coming to personal assistance from other forms of social care, but without an ideological commitment to independent living. There were also differences between people who employed personal assistants to support their disabled children, and those who employed assistants directly on their own behalf.

Differences also reflected known differences in the backgrounds and motivations of personal assistants, who were themselves very diverse. Some people came to personal assistance with training in social care or healthcare, and so had various preconceptions of their own. Others were new to social care. Some people were looking for convenient, flexible work and others were looking for a meaningful long term career. All of these personal characteristics appeared to influence the personal assistance relationship.

In thinking about these different kinds of personal assistance relationship, we expected to be able to develop a classification of 'ideal types' (or models) of relationship. However this suggests an intentionality and complexity to people's thinking which we did not find. We also 
thought we could talk in terms of competing discourses of personal assistance. Yet, partly because there was a lack of consistency and coherence in the way people talked, we came to think in terms of metaphors.

As established, personal assistant is a new role and generates a new relationship. In academic discourse, we might use technical descriptions, such as 'commodified support relationship', but these are not necessarily meaningful to people in their lives, let alone easy to incorporate into everyday discourse. Importantly, the phrase 'personal assistant' is itself a metaphor, drawn from the business world of a professional assistant who supports an executive. Since we lack an established social and cultural understanding of the nature and meaning of personal assistance, it is not surprising that people reach for metaphors to clarify these roles and situations.

In the remainder of this paper, we discuss our findings in terms of the key metaphors which were employed by our interviewees.

\section{Extension of self}

One set of metaphors clustered around the idea of the personal assistant as compensating for what the disabled person physically could not do for themselves. Thus one person said:

I will always say, 'you are an extension of my hands, you have to do what I can't do'... I can't open packets, I can't open the fridge or freezer, and that's what she's there for.

Others also used this notion of extension as a compromise, something that appeared neutral:

I would tend not to use the phrase 'friend', I guess I don't like 'servant' either, really... 'extension', I would say.

Nobody in our study used the phrase 'robot', sometimes found in the personal assistance literature (Guldvik et al, 2014), but as expressed by another interviewee, there was a tendency to highlight the basic character of assistance: 
I need physical help at some times, there's no negotiation on that, you know, I have to get to bed, I need someone to lift and get me out, how else can you describe that? It's just, it's physical, mechanical thing, you know...

Perhaps reflecting this utilitarian emphasis, and drawing on explicit disability rights movement thinking (Gibson et al, 2009), another disabled person said: 'I would describe them as a "worker" and "arms and legs"' (DP30). However, this latter approach was felt to be alienating by one interviewee:

He's a human being, he needs to be treated respectfully, etc. I can't see him being my arms and legs, in that sense.

This informant is responding to the implication in this usage that the personal assistant has no agency or personhood of their own, but must always simply execute the given orders. This may suit some personalities, but many individuals may feel alienated, and end up giving perfunctory service, because they do not feel fully respected.

\section{Staff}

Other people used the term 'staff' and cognate terms such as 'servant'. Thus, for example, one personal assistant interviewed said:

I quite like to see myself as a servant really. I don't feel at all uncomfortable with that term. I am a worker or a servant, but a friendly one.

One mother, who employed a number of personal assistants to support her two children with disabilities, talked throughout her interview in terms of staff, referring to staff meetings, and seeing herself as the manager of a team of staff.

Terms like staff and servant, in the British context, could be interpreted either as connecting to a local authority or private care home context, as with the mother mentioned, or as relating to the popular television period dramas such as 'Upstairs, Downstairs' or 'Downton Abbey' portraying stereotype of wealthy elites with their subordinated servants, which have become 
very popular as forms of mass entertainment, and may therefore influence public perceptions of personal assistance. The entailments here are that the worker is 'seen but not heard'; not a participant in conversations; not eating at the same table; leading a separate existence to the disabled person.

Another personal assistant, who herself had had some social work training in her own native country, resented that she was now being treated as a simple employee:

I didn't realise from the beginning, because of my little knowledge of English...and then with time I noticed that sometimes she was treating me like a servant - 'you haven't done this'... If you want me to be a servant, I can be a servant and only do things that you want me to do, and nothing more...

In other words, there is a risk that when someone is treated as a servant, they will act like a servant, keeping distance and potentially ending up alienated and discouraged. It is also relevant to note that $20 \%$ of care workers in Britain are migrants (Skills for Care 2017), and when there are differences of culture, there is more potential for misunderstandings, and/or power differentials.

\section{Colleague}

The colleague metaphor is potentially more mutual, and more empowering for the employee. The implication of the metaphor is that people are convivial and equal, but that the private realm remains somewhat separate. People may socialise occasionally, but they would not share emotional confidences. They are friendly in the work context, but not more. Thus one interviewee said:

They are friends in the same way a work colleague might be a friend. We can be on friendly terms with each other. I believe this helps the relationship, but they are doing a job and both parties shouldn't forget this.

Not everyone found this a useful approach, however. A personal assistant informant disagreed with the colleague analogy: 
It's different from professional relationships, because you are in the person's house and into their lives completely. It's not as if you are relating to your colleague at work or your boss at work, you are part of their daily routine and you get to know their most personal needs.

\section{Professional}

When people, particularly personal assistants, resorted to the metaphor of professionalism, it seemed to be about asserting separateness. This was a job, and it was not personal. There were clear boundaries - to behaviour, to intimacy, to the working day - and these should not be violated. The professionalism metaphor was also about the implication of a code of conduct, a quality of service in which people could take pride. So, for example, one interviewee also said of one disabled employer:

I felt that he was feeling things towards me that I was not... I was living more a professional kind of relationship... So when it got so personal, I realised that I had to tell $\operatorname{him...}$

\section{Paid friends}

Many people spontaneously came up with the concept of 'paid friends'. This was sometimes because the disabled person had literally recruited a friend to support them. One, for example, said:

We'd been friends for twenty years as being neighbours, and became very friendly and she knew my MS and knew I needed help occasionally... So I thought, well, if she's doing things for me already, why can't I pay her?

The same woman thought of the arrangement in terms of 'doing a favour for a friend, even though they're being paid for it'. The added advantage, according to another participant (DP27), was 'I found it easier to talk to somebody that I knew as well'.

In other cases, a stranger had come to work for the disabled person, and over time had turned 
into a friend:

'I employed people who became friends, and still are friends.'

Sometimes, disabled people were explicit about wanting a friend as much as a worker:

I just very much wanted someone who would be my friend really, and take me out and do nice things... So with L, because I am paying her to be my friend - sounds awful - but I say what I would like to do, and she fits in with me, as opposed to the other way round. $[\ldots]$ she is my friend, but she's not my friend.

This way of thinking about paid friends seems reminiscent of the wealthy lady's companion in the pre-war period, who was more than a servant, but less than a genuine friend; she carried out chores and acted as an assistant, as well as being a social companion.

Personal assistants sometimes found this made the job more satisfying than conventional care work:

She would ask me to do a job, then we would have a coffee or a chat... so it split up the time a bit more, and it invigorated that, having someone to talk to, like you would in a normal job - that's what made it enjoyable. (PA08)

The implication of the term 'paid friend' is that the transaction is not solely a commercial arrangement, but that there is a relationship based on trust and emotional connection. Yet 'paid friend', an obviously ambiguous concept, was a term people sometimes struggled to define:

Perhaps I should say more 'friendly-like', but it does feel that we have got more of a friendship basis... Obviously we're not friends like I am with other friends...

Some disabled people warned against the assumption that the relationship would become a friendship:

I've got friends already. I see my friends, so why do they have to be friends? There's an 
element of friendship there, but it's not social, you don't have to like someone to do a good job, although it helps.'

This relates to the disability rights origins of the personal assistance relationship, which was very much based on separating tasks from emotions, and keeping boundaries between the private and the public. A similar thought was voiced by a personal assistant:

I give my time, and I try to the best as I can to give you a good service, but I am getting money, so it's not like a friendship, it's very different.'

Moreover, there could be risks and costs consequent on the emotional connection associated with friendship:

When you are invested personally, you can easily get hurt.

\section{Family}

Some disabled people went beyond the notion of friendship, to draw on metaphors of relatedness. One disabled woman, who had different personal assistants for each day of the week, she tended to see them as like surrogate daughters:

I just get really mother hen in my old age... it's like I see them all as naughty children, it's quite interesting... They are all female, they're all young women a long way from home because they're Eastern Europeans or whatever, and I admire them greatly.

Another disabled woman spoke about the complexity of the relationship:

She is part of the household, really, because my daughters all love her... I would say it is almost like a family friend - not quite a personal friend.... It's like a forced relationship through what you need... It is a very unusual relationship, it is not a mother-child, it's not a parenting, but it has got all those elements.

Family type relationships seem to depend on the age of the participants. One personal assistant, for example, was a similar age to the young woman she had supported for several 
years. She felt she would be involved in this disabled woman's life in years to come:

I know her so much more than anyone could, because of our relationship. It's more than that, because people can know each other when they're best friends, but with her, it's more a connection that, other people don't know that stuff. Like, maybe a sister. (PA11)

The implication of the family metaphor is that tasks are performed either out of love and / or a sense of duty. The exchange is not solely financial, and it is continuing. Family relationships offer rewards of deep trust and shared emotional confidence. But they leave both parties vulnerable, for example if they end because of the departure of one party, or if they break down.

\section{Implications of metaphors}

In this study, we have found that metaphors were often used when we asked disabled people and personal assistants to talk about roles. Our data echoes the findings of a Japanese study which found that disabled people in centres for independent Iving in Japan characterised their assistants as 'instruments' (functional), 'employees' (task-oriented), 'companions' (interpersonal aspect) and 'social assets' (individuals without disabilities who understand independent living (Yamaki and Yamazaki, 2004). The authors of the study conclude that personal assistance relationships in Japan are multi-faceted. User-directed, user-helper relationships did not develop automatically, and training was required - to ensure agency for users, and to ensure that assistants understand that the disabled person should be in charge. Their findings echo those of Christensen (2012), who found the British approach to personal assistance tends to generated either 'master-servant' or 'solidarity-emotion based' relationships, compared with arrangements in Norway, where the tendency was towards professionalised (and apparently more sustainable and mutually satisfactory) relationships. This suggests our research may have cross-cultural relevance, and that practices in the UK may need to be challenged or developed.

Thinking in terms of metaphors enables us to reveal how the data reflects the diversity of current ways of thinking among both disabled people and their workers. Because there is no 
single, simple meaning to personal assistance, and no accessible definition, people have to find their own way of understanding and explaining the role, the tasks and the relationship. Often they draw on conventionally understood concepts to illuminate this new phenomenon. This makes analysis of metaphors fruitful and relevant. Perhaps in time there will be one or more straightforward models of personal assistance, and possibly even new terminology: at that point, metaphors may no longer be needed, because personal assistance would become a thing in itself. But for now, understandings are contested, and highlighting that seems to have both conceptual and practical value.

Wherever societies have adopted the personal assistance approach to providing care and support to disabled people, there has been an openness and flexibility to the model, which is one of its strengths. Disabled people have usually had the freedom to define and construct personal assistance for themselves. The implication of this is that there is no single model for personal assistance. Moreover, everyone is different, and each relationship is unique. Personal assistance is multi-faceted: a disabled person may have different relationships with different personal assistants. Metaphors are not mutually exclusive; indeed we found one individual referring to several different metaphorical framings. Metaphors are contiguous, sometimes even contingent upon one another: for example, the metaphor someone used for their assistant had implications for the metaphor they used of their relationship with their assistant. If someone was regarded as a 'paid friend' or even as 'family', then they were likely to be companionable, and the disabled person might worry more about their wellbeing.

Personal assistants too have different expectations, and may prefer different ways of relating:

When it comes to being a PA, it depends a lot on variables such as chemistry with the person, boundaries, experience on the part of the user and the PA.

The prior training and experience of the personal assistant, their age and values, will all also contribute to their own framing of the personal assistant relationship.

The 'paid friendship' idea, found in the work of Woodin (2006) and Christensen (2012), is paradoxical, but still helpful. Friendship does not generally involve financial exchange. But it 
does entail reciprocity when it comes to help. Friendship normally involves 'give and take', and a balance over time. Sometimes, disabled people cannot reciprocate practical assistance that friends give them: for example, they may need a lift in someone's car, but they may not be able to give a lift in return, or they may need a lightbulb changed by the neighbour, but might be unable to carry out an equivalent task. This is why personal assistance, as an example of a cash for care arrangement, is such an important and empowering solution; it can enable reciprocity to be restored, removing the potential for dependency or unequal obligation. Moreover, friends are also emotionally reciprocal (they care about each other equally) which, of course, disabled people are very capable of doing with their personal assistants, even if they cannot carry out certain tasks.

In this study, we found that disabled people typically stressed 'friendship' with their assistants, while personal assistants were more likely to talk in terms of 'friendliness'. We interpret this as signalling that workers want to preserve their own privacy and autonomy. Disabled people generally had no choice but to share their private space and feelings; personal assistants only did this up to a point. Friendship has benefits, but also carries risks, because personal assistants may leave their employer and go on to other jobs, which may mean the end of the friendship:

Sometimes it's sad to let go, not let go but... to realise that no one lasts forever, and everyone has got their own lives to lead - and you can't stick to the same person all the time.

\section{Conclusion}

As we found examples of each of the different personal assistant metaphors running smoothly, with both disabled person and worker(s) seeming to be content with their relationship and roles, we cannot recommend one approach as the best for everyone. However, we felt, from our data, that the simple 'staff' or 'extension' metaphor carried with it potential risks for some personal assistants, who may feel alienated, or even exploited. Conversely, the 'family' metaphor entailed risks for both parties, as it could be intense and emotionally fraught. Neither option appeared, to us, as sustainable as the alternative metaphors on offer. 
Problems in personal assistant relationships may arise if there is a lack of clarity. If people are unclear about the metaphor they are using or thinking of, or about the roles they are expecting each other to fulfil, confusion or tension may result, from what might be called 'mixed metaphors'. One person may expect friendship, for example, while the other expects a 'seen and not heard' worker. When personal assistants and come from a different culture there may be additional confusion about the different metaphors the employer and worker may be drawing upon.

Conflict can emerge from 'crossing boundaries', which may be implicit and hidden (Glendinning et al, 2000). Both parties in the personal assistant relationship, we suggest, need to be clear about their expectations. Of course, relationships can and do change. Friendship, for example, may grow between strangers. A member of staff may become a colleague or even a friend over time. So we do not claim that the metaphors and roles are, or should be, static.

In conclusion, we argue that more clarity is needed about how different metaphors shape roles, expectations and the personal assistant relationship itself: 'Disabled people and their attendants are left to grapple with the nature of their relationship privately, away from public conversations about personal assistance' (Kelly, 2011:5).

All of our participants reported having experienced conflict over personal assistance at some point. We found examples of criminality, exploitation and abuse of disabled people by their personal assistants; this unregulated, flexible relationship is thus not a nirvana: it can go wrong, for either party.

Personal assistance covers a multitude of varied roles and relationships. There is no one model, and no clear guidance for managing this complex set of interactions. We agree with Yamaki and Yamazaki (2004) who argue there is a need for training and support for disabled people, as well as for personal assistants, to ensure the relationship goes smoothly. Training and awareness of these relationships may enable a better 'fit' between workers and employers, and avoid the dangers of 'mixed metaphors', conflict and relationship breakdown. 
Tables

Table 1: Disabled Employer Information

\begin{tabular}{|c|c|c|c|c|}
\hline ID & Sex & Interview type & Self-defined impairment & Ethnicity \\
\hline DP01 & $\mathrm{F}$ & Face to face & Familial Dysautonomia & White British \\
\hline DP02 & $\mathrm{F}$ & Face to face & Spinal Cord Injury & White British \\
\hline DP03 & $\mathrm{F}$ & Face to face & Multiple Sclerosis & White British \\
\hline DP04 & $\mathrm{M}$ & Face to face & Multiple Sclerosis & White British \\
\hline DP05 & $M$ & Face to face & Cerebral Palsy & British Asian \\
\hline DP06 & $\mathrm{F}$ & Face to face & Cerebral Palsy & Black British \\
\hline DP07 & $\mathrm{M}$ & Face to face & Cerebral Palsy & British Asian \\
\hline DP08 & $\mathrm{F}$ & Face to face & Muscular Dystrophy & White British \\
\hline DP09 & $\mathrm{M}$ & Telephone & Musculoskeletal (chronic condition) & White Non-British \\
\hline DP10 & $\mathrm{F}$ & Telephone & Physical Impairment & White British \\
\hline DP11 & $\mathrm{F}$ & Face to face & Phocomelia (congenital) & White British \\
\hline DP12 & $\mathrm{M}$ & Telephone & Multiple Sclerosis & White British \\
\hline DP13 & $\mathrm{F}$ & Face to face & Physical Impairment & White British \\
\hline DP14 & $\mathrm{M}$ & Face to face & Spinal Muscular Atrophy & White British \\
\hline DP15 & $\mathrm{F}$ & Face to face & Myalgic Encephalomyelitis & White British \\
\hline DP16 & $M$ & Email & Physical Impairment & White British \\
\hline DP17 & $\mathrm{F}$ & Face to face & Spinal Muscular Atrophy & White British \\
\hline DP18 & $\mathrm{F}$ & Face to face & Friedreich's ataxia & White British \\
\hline DP19 & $\mathrm{F}$ & Face to face & Spinal Cord Injury & White British \\
\hline DP20 & $\mathrm{F}$ & Face to face & Multiple Sclerosis & White British \\
\hline DP21 & $\mathrm{M}$ & Telephone & Physical impairment & White British \\
\hline DP22 & $\mathrm{F}$ & Face to face & Multiple Sclerosis & White British \\
\hline DP23 & $\mathrm{M}$ & Telephone & Physical impairment & White British \\
\hline DP24 & $\mathrm{F}$ & Telephone & Multiple Sclerosis and Sensory Processing & White British \\
\hline DP25 & $\mathrm{F}$ & Face to face & Myalgic Encephalomyelitis & White British \\
\hline DP26 & $M$ & Face to face & Muscular Dystrophy & White Non-British \\
\hline DP27 & $\mathrm{F}$ & Telephone & Mother to daughter with Down's syndrome & White British \\
\hline DP28 & $\mathrm{F}$ & Face to face & Mother to son with learning disability & White British \\
\hline DP29 & $\mathrm{F}$ & Telephone & Mother to son with Down's syndrome & White British \\
\hline DP30 & $\mathrm{M}$ & Telephone & Physical Impairment & White British \\
\hline
\end{tabular}


Table 2: Personal Assistant Information

\begin{tabular}{|c|c|c|c|}
\hline ID & Sex & Interview type & Ethnicity \\
\hline PA01 & F & Face to face & White Non-British \\
\hline PA02 & F & Face to face & White British \\
\hline PA03 & F & Face to face & White British \\
\hline PA04 & M & Face to face & White British \\
\hline PA05 & F & Face to face & British Asian \\
\hline PA06 & M & Face to face & White Non-British \\
\hline PA07 & M & Telephone & White British \\
\hline PA08 & F & Face to face & White British \\
\hline PA09 & M & Telephone & White British \\
\hline PA10 & F & Telephone & Black Non-British \\
\hline PA11 & F & Telephone & White British \\
\hline PA12 & F & Telephone & White British \\
\hline PA13 & F & Telephone & White British \\
\hline PA14 & F & Telephone & White British \\
\hline PA15 & F & Telephone & White British \\
\hline PA16 & M & Telephone & White British \\
\hline PA17 & f & Telephone & White British \\
\hline PA18 & F & Telephone & White British \\
\hline PA19 & F & Telephone & White British \\
\hline PA20 & M & Telephone & White British \\
\hline PA21 & F & Telephone & White British \\
\hline PA22 & F & Telephone & White British \\
\hline PA23 & F & Face to face & White Non-British \\
\hline PA24 & F & Telephone & White British \\
\hline PA25 & F & Telephone & White British \\
\hline PA26 & F & Telephone & White British \\
\hline PA27 & F & Telephone & White British \\
\hline PA28 & F & Telephone & White British \\
\hline
\end{tabular}




\section{References}

Ahlström, G. and Wadensten, B. (2012) Enjoying work or burdened by it? How personal assistants experience and handle stress at work, Journal of Social Work in Disability \& Rehabilitation, 11(2) 112-27 Charmaz, K. (2006) Constructing grounded theory: a practical guide through qualitative analysis, London: Sage Publications.

Christensen, K. (2012) Towards sustainable hybrid relationships in cash-for-care systems, Disability and Society 27(3) 399-412.

Deignan, A. (2010) The evaluative properties of metaphors, in G. Low, A. Deignan and L.Cameron (eds) Researching and applying metaphor in the real world, Amsterdam: John Benjamins Publishing Company, pp 357-74.

Finkelstein, V. (1999) Professions allied to the community (disabilitystudies.leeds.ac.uk/files/library/finkelstein-pacall.pdf).

Gibson, B. E., Brooks, D., DeMatteo, D. and King, A. (2009) Consumer-directed personal assistance and 'care': perspectives of workers and ventilator users. Disability \& Society, 24(3) 317-30.

Glendenning, C., Halliwell, S., Jacobs, S., Rummery, K. and Tyrer, J. (2000) New kinds of care, new kinds of relationships: how purchasing services affects relationships in the giving and receiving of personal assistance, Health and Social Care in the Community, 8(3) 201-11.

Guldvik, I., Christensen, K. and Larsson, M. (2014) Towards solidarity: working relations in personal assistance, Scandinavian Journal of Disability Research 16 (supl): 48-61.

International Labour Organization (2011) C189 - Domestic Workers Convention, Geneva: ILO.

Kelly, C. (2011) Making 'care' accessible: Personal assistance for disabled people and the politics of language, Critical Social Policy 31(4) 1-21.

Lakoff, G. and Johnson, M. (1980) Metaphors we live by, Chicago: University of Chicago Press.

Morris, J. (1993) Independent lives? Community care and disabled people, London: Macmillan.

Maasen, S., Mendelsohn, E. and Weingart, P. (1995) (eds) Biology as society, society as biology:

Metaphors, Amsterdam: Kluwer Academic Publishers.

Maasen, S. (2000) Metaphors in the social sciences: making use and making sense of them, in F. Hallyn (ed) Metaphor and analogy in the social sciences, London: Springer, pp199-244.

Martin, E. (1991) The egg and the sperm: How science has constructed a romance based on stereotypical male-female roles, Signs: Journal of Women in Culture and Society, 16(3): 485-501.

Moore, H. (2004) Global anxieties: Concept-metaphors and pre-theoretical commitments in anthropology. Anthropological Theory, 4(1) 71-88.

Morris, J. (1997) Care of empowerment? A disability rights perspective, Social Policy \& Administration, 31(1) 54-60.

Pillinger J. (2011) Quality healthcare and workers on the move, Public Services International, 
International Migration and Women Health and Social Care Workers Programme, PSI, Ferney-Voltaire.

Semino, E., Demjen, Z., Demmen, J., Koller, V., Payne, S., Hardie, A. and Rayson, P. (2017) The online use of violence and journey metaphors by patients with cancer, as compared with health professionals: a mixed methods study', BMJ Supportive and Palliative Care 7 (1) 60-6.

Shakespeare, T. (2014) Disability rights and wrongs revisited, London: Routledge.

Skills for Care (2017) Nationality of the adult social care workforce, NMDS-SC briefing 28.

https://www.nmds-sc-online.org.uk/Get.aspx?id=/Research/Briefings/Briefing 28- Nationality - final.pdf

Sontag, S. (1978) IIlness as metaphor, New York: Farrar, Straus and Giroux.

Ungerson, C. (1999) 'Personal assistants and disabled people: an examination of a hybrid form of work and care', Work, Employment and Society, 13(4): 583-600.

Ungerson C. and Yeandle S. (eds) (2007) Cash for care in developed welfare states, Basingstoke: Palgrave Macmillan.

Wadensten, B. and Ahlström, G. (2009) Ethical values in personal assistance: Narratives of people with disabilities, Nursing ethics, 16(6) 759-74.

Wood, R. (1991) Care of disabled people, in G. Dalley (ed) Disability and social policy, London: Policy Studies Institute, pp. 199-202.

Woodin, S.L. (2006) Social relationships and disabled people: the impact of direct payments, University of Leeds.

Yamaki, C. and Yamazaki, Y. (2004) 'Instruments', 'employees', 'companions', 'social assets': understanding relationships between persons with disabilities and their assistants in Japan, Disability and Society, 19(1): 31-46. 